\title{
Identifying markers associated with yield traits in Nagina22 rice mutants grown in low phosphorus field or in alternate wet/dry conditions
}

\author{
Poli Yugandhar ${ }^{1}$, Ramana Kumari Basava ${ }^{1}$, Subrahmanyam Desiraju ${ }^{1}$, Sitapati Rao Voleti ${ }^{1}$, R.P. \\ Sharma ${ }^{2}$, Sarla Neelamraju ${ }^{1 *}$ \\ ${ }^{1}$ ICAR - Indian Institute of Rice Research (Directorate of Rice Research), Rajendranagar, Hyderabad- 500030, \\ India \\ ${ }^{2}$ ICAR - National Research Centre on Plant Biotechnology, IARI, New Delhi-110012, India
}

*Corresponding author: sarla_neelamraju@yahoo.com; nsarla@drricar.org

\begin{abstract}
Mutants are powerful genetic resources in plant breeding and functional genomics studies. Sixty seven stable ethyl methane sulphonate (EMS) induced rice mutants and the wild type parent Nagina 22 (N22) were characterized for plant height, tiller number, panicle number and grain yield under normal, low $\mathrm{P}$ field and alternate wet and dry (AWD) conditions in the same season. They were also genotyped with 44 SSR markers and four Pup1 (Phosphorus uptake1) gene specific markers. Genetic diversity was analysed by combining phenotype and marker data using Ward- MLM method. Single marker analysis showed significant association of four markers RM19696, RM263, RM3688 and RM1942 with grain yield in all three conditions. K-1, a Pupl gene specific marker was significantly associated with tiller number only under low $\mathrm{P}$ conditions. The average dissimilarity between mutants was 0.86 and cophenetic correlation coefficient was 0.74 . Six mutants were selected as gain-of-function mutants as they showed significantly higher grain yield in all three conditions, compared with N22. The selected mutants are an important resource for gene discovery for enhanced tolerance to low $\mathrm{P}$ and water stress conditions and associated markers can be useful in marker assisted selection.
\end{abstract}

Keywords: AWD; low P; mutants; Pupl marker; tiller number.

Abbreviations: P_Phosphorus; AWD _alternate wetting and drying; SSR_Simple sequence repeats; N22_Nagina 22; EMS_ethyl methane sulfonic acid; SMA_Single marker analysis.

\section{Introduction}

Phosphorus $(\mathrm{P})$ is an essential macronutrient required for plant growth. It is a significant component of nucleic acids and cell membranes and plays an important role in lipid metabolism. $\mathrm{P}$ is also required for photosynthesis and respiration processes. One third of the agricultural land in the world does not have adequate amount of $\mathrm{P}$ in the soil for optimum plant growth and development (MacDonald et al., 2011). Availability of $P$ from soil to plant is limited due to its low mobility in nature and is often a limiting factor for crop yield. Application of rock phosphate, the major source of $\mathrm{P}$ fertilizers, is uncertain as it is non renewable resource and the world reserves of rock phosphate are likely to be exhausted (Wiel et al., 2016). Hence, P fertilizers are becoming expensive and thus lower the profit to farmers in low input rainfed agricultural systems. On the other hand, abundant use of $\mathrm{P}$ fertilizers derived from livestock manures, a common practice in intensive agriculture, affects environment in the form of eutrophication of freshwater habitats (Tiessen, 2008; Ashley et al., 2011). One approach suggested to tackle this problem of low or excess use of $\mathrm{P}$ in farming is the identification and development of genotypes with high phosphorous use efficiency (PUE) in low P soils without compromising yield (Aluwihare et al., 2016; Rose et al., 2010, 2011, 2012, 2015). More than PUE, it is the ability to tolerate $\mathrm{P}$ deficiency to different extent and yet give high yield which is more important. Tolerance to low $\mathrm{P}$ is a complex trait involving plant architectural, physiological, biochemical and molecular mechanisms that provide plasticity. Therefore, there is a necessity to identify and develop new genetic resources to explore diverse molecular mechanisms for $\mathrm{P}$ deficiency tolerance.

Rice is the major irrigated cereal crop and it requires two to three times more water than other crops such as wheat and maize (Bouman et al., 2007). It requires $700-1500 \mathrm{~mm}$ of water per cropping season under normal traditional irrigation practices (Bhuiyan, 1992). It is estimated that by 2025, 15 million ha of Asian rice production under irrigation will experience physical water scarcity as the per capita available water resources in Asia are expected to decline by 15-54 percent (Tuong and Bouman, 2003; Rahman and Bulbul, 2015). However more irrigation water is required to increase rice production to meet growing food demand. Hence, efficient water management practices are needed in rice cultivation by adopting water-saving irrigation technologies (WSI). Alternate wetting and drying (AWD) is one of the most commonly used practices of WSI technique. In this practice, irrigation water is applied to achieve alternate flooded and non-flooded soil condition. The first treatment of draining the field starts at 1 to 2 weeks after transplanting until the water level reaches $15 \mathrm{~cm}$ below the soil surface. The field is re-flooded to a ponded depth of around $5-10 \mathrm{~cm}$. This irrigation scheme is followed throughout the cropping season except from 1 week before and 1 week after flowering (Siopongco, et al., 2013). AWD irrigation system reduced 
irrigation water input by up to $38 \%$ without reduction in yield with large scale adoption in Philippines, Vietnam and Bangladesh (Lampayan et al., 2015). Zhi and Cui (2001) reported that irrigation water use was reduced by $7-25 \%$ with AWD technique and Rahman and Bulbul (2015) showed that AWD saved $24-28 \%$ of irrigation water compared to continuous flooding in Bangladesh. AWD irrigation approach in India can reduce water use by about $40-70 \%$ compared to the traditional practice of continuous submergence, without significant yield loss (Singh et al., 1996, Rejesus et al., 2010). Genetic variation produced by natural and artificial mutations is the basis of selection in crop breeding. Use of chemically induced mutants such as ethyl methane sulfonic acid (EMS) has helped to create useful genetic variations in the past (Bhat et al., 2007; Till et al., 2007; Henry et al., 2014; Mohapatra et al., 2014). It has been shown that mainly GC to AT transitions were induced by EMS in Arabidopsis, maize and wheat, (Till et al., 2003; Till et al., 2004; Slade, 2005). But in rice, it was reported that $70 \%$ mutations were $\mathrm{GC}$ to $\mathrm{AT}, 11 \%$ AT to $\mathrm{GC}, 4 \% \mathrm{GC}$ to $\mathrm{TA}$, and $15 \%$ AT to TA (Till et al., 2007). This was consistent with mutational spectrum of barley (Caldwell et al., 2004). Such mutations may in turn lead to other mutations if the initial mutations were in genes for DNA repair enzymes, or genes that help suppress transposon activation, for example.

A large number of rice mutant lines have been produced and studied with the aim of gene discovery for important traits and assigning functions to genes (Mithra et al., 2016). The mutant lines exhibiting significantly higher grain yield or higher tolerance to nutrient deficiency or abiotic stresses or other traits can be used for rice breeding by conventional backcrossing along with molecular marker-assisted selection (Jiang and Ramachandran, 2010; Sikora et al., 2011). EMS induced rice mutants were used to investigate the complex mechanism involved in water and salt stress tolerance (Huang et al., 2009; Zhou et al., 2013). The morphological, physiological and proteomic characterization of some EMS induced mutants showed more tolerance to abiotic stresses for example salt and heat in contrast to their respective wild type lines (Ghaffari et al., 2014; Poli et al., 2013; Nakhoda et al., 2012; Mithra et al., 2016). However, there are no previous reports of screening rice mutants for tolerance to low $\mathrm{P}$ at field level and also under AWD conditions.

Assessing genetic diversity is important in breeding programs to know the available genetic variability. Genetic diversity has been comprehensively analysed in rice, wheat, maize, barley and soybean. Simple sequence repeats (SSR) or microsatellite markers have been widely used due to their codominant nature and repeatability. SSR markers were also used to identify molecular diversity induced through EMS mutations in various crops for example in ground nut (Goswami et al., 2013), in mung bean (Singh et al., 2012) and in chick pea (Khan et al., 2010).

Genetic diversity in rice is usually estimated using either quantitative data such as plant height, number of tillers and panicles, days to flowering, days to maturity and yield traits or molecular marker data such as SSR markers and ISSR markers individually (Prasanth et al., 2016; Nachimuthu et al., 2015 ; Turki et al., 2015;). Both phenotype and molecular data were used to determine genetic diversity and group genotypes using Ward-MLM method in corn (Franco et al., 2005; Ortiz et al., 2008), wheat (Geleta and Heinrich 2012), tomato (Gonçalves et al., 2009), beans (Barbé et al., 2010), capsicum (Sudré et al., 2010), banana (Pestana et al., 2011; Reis et al., 2015) and cassava (Oliveira et al., 2015).

Nagina 22 (N22) is a deep-rooted, drought and heat tolerant upland aus variety widely used as a donor for heat tolerance
(Markandeya et al., 2007; Jagadish et al., 2008). In India, 20,000 stable EMS induced mutant lines of N22 have been developed as a national resource for functional genomic studies in rice (Mohapatra et al., 2014, Mithra et al., 2016). The objective of the present work was 1) to evaluate EMS induced N22 mutants for phenotypic variation under three field environments - normal irrigated, low P soil and AWD conditions, 2) to study genetic diversity using phenotype and SSR data using Ward-MLM method and 3) to identify markers associated with plant height, tiller number, panicle number and yield per plant under normal, low $\mathrm{P}$ and AWD conditions in field.

\section{Results}

\section{Field experiments}

\section{Normal vs low P conditions}

ANOVA results showed statistically significant effects on all four traits (plant height, tiller number, number of panicles and yield/plant) among mutants, between normal and low $\mathrm{P}$ conditions and interaction between mutants and treatments (Table1). Descriptive statistics and absolute mean values of three replications for the four traits in each genotype under normal conditions and low $\mathrm{P}$ conditions during wet season 2012 are shown in Supplementary Table 1. All traits were normally distributed with absolute values of skew and kurtosis of $<1.0$ in the mutant population. A highly positive correlation among panicle number, tiller number and yield per plant was observed under both low $\mathrm{P}$ and AWD treatments (Fig. 1).

In low $\mathrm{P}$, plant height was significantly more in only three mutants, NH404 (8.7\%), NH418 (15.3\%) and NH685 $(19.5 \%)$ when compared with normal condition. NH101 was the tallest among all mutants in both normal $(101 \mathrm{~cm})$ and low $\mathrm{P}(85 \mathrm{~cm})$ fields. Both number of tillers and panicles decreased in low P in all mutants and N22. However, the percent decrease was significantly less in 46 mutants for tiller number and 37 mutants for panicle number compared to N22. Similarly, there was significant reduction in yield per plant under low $\mathrm{P}$ condition in all mutants when compared with normal conditions. However, when compared with N22, the percent reduction in yield per plant was significantly less in 26 mutants and significantly more in 11 mutants. NH377 had the least percent reduction in yield per plant $(38.24 \%)$. In addition, ten mutants either did not flower (eg. NH101) or flowered but did not set seed under low P (Supplementary Table 1).

The mean yield per plant in $\mathrm{N} 22$ was $13.84 \mathrm{~g}$ in normal and $1.61 \mathrm{~g}$ in low $\mathrm{P}$ conditions thus showing $88 \%$ reduction. Three mutants (NH669, NH686 and NH787) exhibited maximum yield per plant in both normal (22-27 g) and low $\mathrm{P}$ treatments (8.2- $8.9 \mathrm{~g})$, with $63-68 \%$ reduction in yield due to low P stress (Supplementary Table 1).

\section{Normal vs AWD conditions}

ANOVA revealed statistically significant differences in all traits among mutants, between normal and AWD conditions and also due to interaction between mutants and treatments (Table1). Absolute mean values of three replications for all four morphological traits of each genotype under normal conditions and AWD conditions in wet season 2012 are shown in Supplementary Table 1. The correlations were similar to that observed in normal vs low P conditions (Fig. 1). Plant height reduced up to $30 \%$ in AWD in all lines 
Table 1. Analyses of variance for N22 mutants under normal Vs low P and AWD conditions.

\begin{tabular}{|c|c|c|c|c|c|c|c|c|c|}
\hline \multirow[b]{2}{*}{ Source } & \multicolumn{3}{|c|}{ Normal Vs low P conditions } & \multicolumn{6}{|c|}{ Normal Vs AWD conditions } \\
\hline & DF & $\begin{array}{l}\text { Plant height } \\
(\mathrm{cm})\end{array}$ & Tiller number & $\begin{array}{l}\text { Panicle } \\
\text { number }\end{array}$ & $\begin{array}{l}\text { Yield per plant } \\
(\mathrm{g})\end{array}$ & $\begin{array}{l}\text { Plant height } \\
(\mathrm{cm})\end{array}$ & Tiller number & $\begin{array}{l}\text { Panicle } \\
\text { number }\end{array}$ & Yield per plant $(\mathrm{g})$ \\
\hline Genotype & 67 & $23.09 * * *$ & $7.55 * * *$ & $11.8^{* * * *}$ & $40.77 * * *$ & $89.73 * * *$ & $17.4 * * *$ & $23.53 * * *$ & $83.7^{* * * *}$ \\
\hline Treatment & 1 & $797.03 * * *$ & $1514.21 * * *$ & $1728.23 * * *$ & $11381.1 * * *$ & $946.18 * * *$ & $582.68 * * *$ & $370.86 * * *$ & $445.79 * * *$ \\
\hline Genotype*Treatment & 67 & $16.71 * * *$ & $5.79 * * *$ & $7.43 * * *$ & $18.86^{* * *}$ & $6.12 * * *$ & $2.32 * * *$ & $2.3 * * *$ & $7.27 * * *$ \\
\hline Error & 272 & & & & & & & & \\
\hline Grand mean & - & 73.304 & 11.324 & 10.235 & 9.1076 & 74.547 & 13.299 & 12.623 & 14.003 \\
\hline $\mathrm{CV}$ & - & 5.6 & 17.66 & 18.22 & 13.16 & 3.96 & 11.81 & 12.06 & 9.82 \\
\hline
\end{tabular}

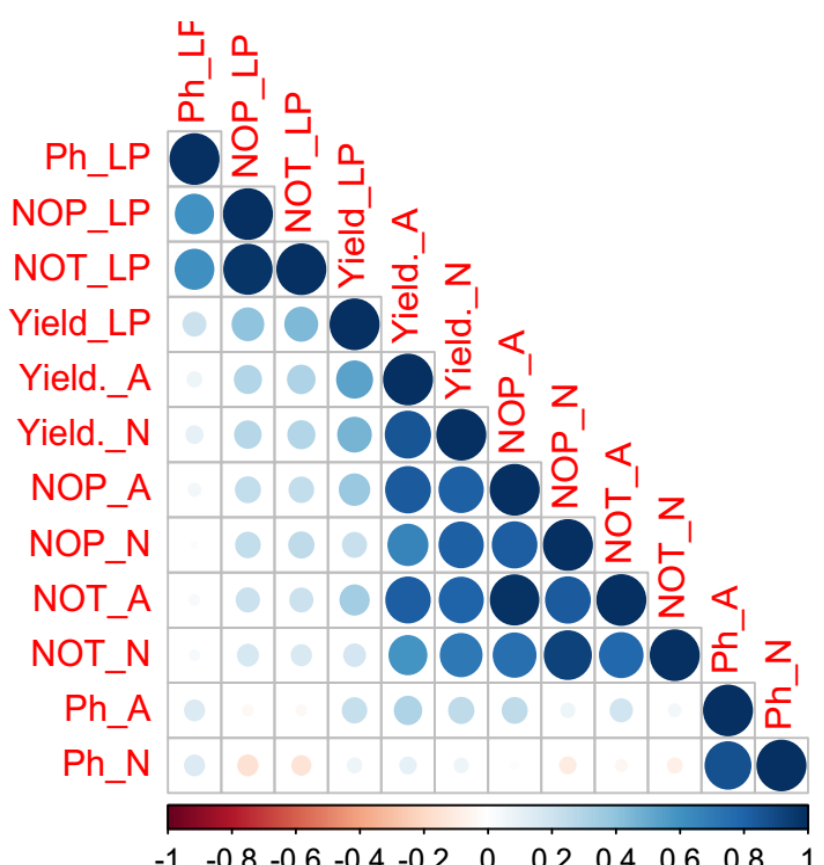

Fig 1. Pearson correlation among traits under normal, low P and AWD irrigation.Ph: Plant height; NOT: Number of tillers; NOP: Number of panicles; Yield: Yield per plant;

N: Normal; LP: Low P soil; A: AWD irrigation. The bar below the picture represents Pearson correlation value, Blue circles indicate positive correlation and red circles indicate negative correlation 
Table 2. Significant results of single marker analysis of N22 mutants with F value under normal, low P and AWD irrigation.

\begin{tabular}{|c|c|c|c|c|c|}
\hline Trait & & & Normal & Low P field & AWD \\
\hline & Marker & Chromosome & $\mathrm{F}$ & $\mathrm{F}$ & $\mathrm{F}$ \\
\hline \multirow[t]{5}{*}{ Plant height } & RM541 & 6 & $10.29 * *$ & - & $13.27 * * *$ \\
\hline & RM304 & 10 & $3.15^{*}$ & - & - \\
\hline & RM1920 & 2 & $5.80 * * *$ & - & - \\
\hline & RM224 & 11 & - & $2.41 *$ & $3.49 *$ \\
\hline & RM449 & 1 & - & - & - \\
\hline \multirow[t]{8}{*}{ Number of tillers } & RM19697 & 6 & $3.64 * *$ & - & $7.28 * * *$ \\
\hline & RM263 & 2 & $6.31 * *$ & - & $4.5^{* *}$ \\
\hline & RM3688 & 2 & $12.2 * * *$ & - & $20.75 * * *$ \\
\hline & RM1942 & 2 & $5.59 * *$ & - & $11.68 * * *$ \\
\hline & RM8007 & 7 & $4.81 *$ & - & \\
\hline & $\begin{array}{l}\text { K-1 (pup gene } \\
\text { specific marker) }\end{array}$ & 12 & - & $3.77 *$ & - \\
\hline & RM205 & 9 & - & - & $4.24 * *$ \\
\hline & RM260 & 12 & - & - & $3.21 *$ \\
\hline \multirow{6}{*}{ Number of panicles } & RM19697 & 6 & $4.41 * *$ & - & $7.34 * * *$ \\
\hline & RM263 & 2 & $6.03 * *$ & - & $4.63 * *$ \\
\hline & RM3688 & 2 & $12.71 * * *$ & - & $18.88 * * *$ \\
\hline & RM1942 & 2 & $7.34 * *$ & - & $13.21 * * *$ \\
\hline & RM205 & 9 & - & - & $3.18 *$ \\
\hline & RM260 & 12 & - & - & $3.41 *$ \\
\hline \multirow[t]{8}{*}{ Yield per plant } & RM19697 & 6 & $5.68 * * *$ & $4.48 * *$ & $7.14 * * *$ \\
\hline & RM263 & 2 & $5.97 * *$ & $3.98^{*}$ & $3.93^{*}$ \\
\hline & RM3688 & 2 & $10.8^{* *}$ & $12.68 * * *$ & $14.66 * * *$ \\
\hline & RM1942 & 2 & $5.74 * *$ & $7.73 * * *$ & $7.5 * * *$ \\
\hline & RM242 & 9 & $3.16^{*}$ & - & - \\
\hline & RM1 & 1 & $3.98 *$ & - & $4.04 *$ \\
\hline & RM260 & 12 & - & $3.47 *$ & - \\
\hline & RM205 & 9 & - & - & $4.24 * *$ \\
\hline
\end{tabular}

***Significant at 0.001 level of probability; ** Significant at 0.01 level of probability; $*$ Significant at 0.05 level of probability.

Note: Markers information is available at http://www.gramene.org/markers/microsat.

\section{Dendrogram}



Fig 2. Dendrogram of 67 N22 rice mutants and N22 based on quantitative data (yield related traits in three environments) and 48 markers data and using the UPGMA method in DARwin 
except NH8 which showed a $2 \%$ increase but it was not significant. Similarly, number of tillers and panicles reduced upto $61 \%$ in all lines in AWD except in NH125 and NH444 which showed a non significant increase compared to normal irrigation. Yield per plant also decreased in AWD in all mutants except in three mutants which showed a nonsignificant increase. NH221 showed the maximum yield reduction of $71.24 \%$ and $\mathrm{NH} 123$ the least $(1.1 \%)$ compared to $19.22 \%$ in $\mathrm{N} 22$.

\section{Genetic diversity and molecular analysis}

Forty four SSR markers and 4 Pupl specific markers amplified 95 alleles in all. Dissimilarity matrices were prepared separately with genotyping data and morphological data in three environments. The correlation between these two distance matrices was very low $(r=0.0199)$ and the genetic variability was analysed by combining both genotyping and morphological data using Ward-MLM method. The distance among all mutants ranged from 0.17 to 1.96 with average distance of 0.861 and cophenetic correlation coefficient was $0.739(\mathrm{p}<0.01)$. As per pseudo-F and pseudo- $\mathrm{t}^{2}$ criteria, the optimum number of groups was five. Among the five clusters, cluster I had 14 mutants, cluster II had 12 mutants, cluster III had 14 mutants, cluster IV had N22 and 14 mutants and cluster V had 13 mutants (Fig. 2). The closest mutants were NH664 and NH427 with 0.17 genetic distance and the most dissimilar were two tall and stay green mutants $\mathrm{NH} 363$ and $\mathrm{NH} 162$ with genetic distance 1.96 . These results revealed clear genetic variability for 4 traits among N22 mutants in the three conditions.

\section{Single marker analysis}

$\mathrm{F}$ values and significant marker-trait associations between 48 markers and four traits in normal, low $\mathrm{P}$ and AWD are listed in Table 2.

\section{Marker trait associations in normal conditions}

Two loci RM541 and RM1920 on chromosome 2 and RM304 on chromosome 10 were significantly associated with plant height under normal conditions. The two tall mutants NH363 and NH101 showed a different allele compared to N22 allele at locus RM1920. Four markers RM263, RM3688 and RM1942 on chromosome 2, and RM19697 on chromosome 6 were significantly associated with number of tillers, number of panicles and yield per plant. In addition, RM8007 was associated with only number of tillers and RM242 and RM1 with only yield per plant. The three mutants NH719, NH733 and NH686 which showed significantly higher yield per plant shared the same allele at loci RM19697, RM242, RM1, RM263, RM3688, RM1942 and RM8007.

\section{Marker trait associations in low $P$ conditions}

RM224 was significantly associated with plant height and the allele at this locus was similar in 44 mutants whose height was significantly more in control condition than in low $\mathrm{P}$. Only one marker K-1 out of the four Pupl specific markers was significantly associated with number of tillers and showed a clearly different allele in mutants with high tiller number in low P. Five loci RM19697, RM263, RM3688, RM1942 and RM260 were significantly associated with yield per plant. The alleles at RM19697, RM263 and RM260, were similar in 17 mutants including six mutants with higher grain yield per plant in low $\mathrm{P}$.

\section{Marker trait associations in AWD conditions}

Two markers RM541 and RM449 were significantly associated with plant height and the allele in notably tall mutants in AWD was different from N22 allele. Five markers RM19697, RM263, RM3688, RM1942 and RM205 were significantly associated with number of tillers and panicles and yield per plant. In addition, RM260 was linked to number of tillers and panicles and RM1 to yield per plant. Alleles at loci RM19697, RM1 and RM205 were similar in 17 mutants group showing higher tiller and panicle number under AWD and different from corresponding N22 allele. In all, 15 markers out of 48 were associated with plant height, number of tillers, number of panicles and yield per plant based on single marker analysis. In the current study, four markers RM19697 (chromosome 6), RM263 (chromosome 2), RM3688 (chromosome 2) and RM1942 (chromosome 2) were associated significantly with yield per plant in all the three conditions. These markers were also associated with tiller number and panicle number under normal and AWD conditions but not in low P. In low P, only K-1 (Pupl gene) was associated with tiller number.

\section{Discussion}

Four traits (plant height, number of tillers, number of panicles and yield per plant) showed significant differences among themselves and also between treatments of normal vs low $\mathrm{P}$ soils and normal vs AWD. This indicates the existence of variation in the mutants. Three mutants (NH669, NH686 and NH787) exhibited maximum yield per plant in both normal $(22-27 \mathrm{~g})$ and low $\mathrm{P}$ treatments $(8.2-8.9 \mathrm{~g})$ hence were considered as the best mutants under both normal as well as in low $\mathrm{P}$ conditions. The reduction in yield due to $\mathrm{P}$ stress in these three mutants was $63-68 \%$. Next to these three mutants, there were another set of three mutants (NH355, NH363 and NH719) which performed well as they showed $7 \mathrm{~g}$ yield per plant under low $\mathrm{P}$ conditions with $70-73 \%$ reduction in yield when compared with that of normal condition. Though NH377 exhibited least percent reduction in yield per plant in low $\mathrm{P}$ stress but it did not give good absolute yield under both normal $7.88 \mathrm{~g}$ as well as low $\mathrm{P}$ $(4.86 \mathrm{~g})$. Hence, this mutant can be exploited for low $\mathrm{P}$ tolerance in genomics and breeding programme but may not be commercially important. Similarly, NH101 was the tallest mutant but it did not flower under low $\mathrm{P}$ and can be used to map genes for low $\mathrm{P}$ susceptibility as loss-of-function mutant for flowering in low $\mathrm{P}$.

There are very few studies on identification or development of rice cultivars tolerant to low $\mathrm{P}$ conditions at field level as maintenance and preparation of a field with low phosphate needs much more attention than a normal field and also due to lack of proper screening methods, for traits that confer low P tolerance (Panigrahy et al., 2014). Aluwihare et al. (2016) selected low $\mathrm{P}$ tolerant rice genotypes by growing plants in pots filled with soil, collected from cultivated field without $P$ fertilizer application for past 40 years.

There was significant reduction in trait values due to water stress under AWD in mutants or N22 when compared with normal flooded irrigation. However, a few mutants performed better than N22. Two mutants NH355 and NH787 showed highest yield per plant $(25 \mathrm{~g})$ under AWD conditions. These two mutants also exhibited maximum yield per plant in normal field $(27 \mathrm{~g})$ with only $6 \%$ reduction in yield due to water stress. The percent reduction in yield in N22 was $19.22 \%$. There were three other mutants (NH363, NH686 and NH719) which were next as they exhibited better yield per 
plant (23g) under AWD conditions with 11-15\% reduction in yield (except in $\mathrm{NH719}$, showed equal yield as in normal) when compared with that in normal conditions $(23-27 \mathrm{~g})$. NH363 was an exceptional mutant having maximum plant height as well as high grain yield. Thus NH363 is a gain of function mutant for both plant height and grain yield in both normal and AWD conditions. NH221 and NH407 showed minimum yield per plant $(3.27 \mathrm{~g}$ and $4.08 \mathrm{~g})$ with $71 \%$ and $61 \%$ reduction respectively in AWD conditions when compared with normal irrigation condition. Alternate wet and dry treatment increased the grain filling rate, shortened grain filling period and enhanced whole plant senescence in rice (Zhang et al., 2012).

The quantitative data and SSR marker data revealed different patterns of dissimilarity among the matrices generated; hence, a combined analysis approach offers a better assessment of the real variability. The hierarchical dendrogram broadly clustered the rice genotypes into five major groups. This indicates a high level of genetic diversity in mutants. Wild type $\mathrm{N} 22$ had minimum dissimilarity with NH218 and maximum with NH355 (1.28). Out of six best mutants (gain of function) selected for grain yield and low $\mathrm{P}$ tolerance, four (NH355, NH787, NH686 and NH669) were in the same cluster with dissimilarity ranging from 0.27 to 0.42 . Likewise, two tall mutants (NH363 and NH101) were in the same cluster II. This indicates the effectiveness of WardMLM method of combined data analysis of both quantitative and molecular data in grouping rice genotypes. The results also show the effectiveness of EMS in inducing higher yield in some mutant lines as compared to N22 both in normal and two adverse soil conditions. Thus, it appears from the phenotype that a large number of genome wide mutations with large effects on phenotype were created in these mutants even though only 48 loci were tested.

Plants have different morphological, physiological and biochemical mechanisms such as root growth and architecture, the release of root exudates and associations with soil microorganisms (Wiel et al., 2016; Vandamme et al., 2016; White and Hammond, 2008). Extensive work has been carried out to map QTLs for P uptake and PUE and relevant QTLs have been identified in rice (Wissuwa et al., 1998; Wissuwa et al., 2002; Shimizu et al., 2004; Lang and Buu, 2006; Zhang et al., 2009, Gamuyao et al., 2012; Wiel et al., 2016). Phosphorus uptake 1 (Pupl) and phosphorus starvation tolerance 1 (PsTOL1) QTLs lead to efficient $\mathrm{P}$ uptake and larger root system under P deficient conditions to take up more phosphorus in Kasalath, an Indian aus variety (Wissuwa et al., 2002; Gamuyao et al., 2012). Tyagi et al. (2012) reported two rice genotypes LR 23 (with Pup1) and LR 26 (without Pup1) as tolerant to low P. Dkhar et al. (2014) studied these two genotypes further and revealed differential expression of two genes MO5 (LOC_Os02g29620) and MO7 (LOC_Os03g28920) involved in maintaining cellular homeostasis under low $\mathrm{P}$ conditions in these two low P tolerant rice genotypes. In LR 23, these two genes (MO5 and MO7) were down regulated where as in LR 26, they were up regulated. These results indicate there may be diverse mechanisms of $\mathrm{P}$ deficiency tolerance in different genotypes. N22 is also an aus variety known to have Pupl genes (Tyagi et al., 2012). Tiller number, number of roots, and shoot biomass per plant is associated with phosphorus deficiency tolerance (Raghothama, 1999; Wissuwa and Ae, 2001). A larger genetic variation for $P$ uptake traits relative to $\mathrm{P}$ utilization has also been reported in wheat, maize, rice, sorghum and pearl millet (Jones et al., 1989; Wissuwa et al., 1998; Parentoniet al., 2010; Leiser et al., 2014; Gemenet et al., 2015).
In the current study, four markers RM19697 (chromosome 6), RM263 (chromosome 2), RM3688 (chromosome 2) and RM1942 (chromosome 2) were associated significantly with yield per plant in all the three conditions. These markers were also associated with tiller number and panicle number under normal and AWD conditions but not in low P. This shows that the genomic regions responsible for grain yield and number of tillers were different under AWD and low $\mathrm{P}$ stress. In low P, only K-1 marker of Pupl gene was associated with tiller number but not with yield. Thus both presence of K-1 or tiller number in low $\mathrm{P}$ can be taken as a surrogate for low $\mathrm{P}$ tolerance. The sequenced gene, Pupl in Kasalath rice variety was reported to provide tolerance to $\mathrm{P}$ deficiency under field conditions in Japan (Wissuwa et al., 1998; Wissuwa et al., 2002; Chin et al., 2010, 2011) and it was independently mapped on chromosome 12 by Ni et al. (1998). Introgression lines with Pup1 region in different genetic backgrounds have the potential to significantly increase grain yield under $P$ deficient field conditions (Chin et al., 2011). In the present study also, it is significant that $\mathrm{K}-1$ (one of the Pup1 markers) was linked to tiller number only in low $\mathrm{P}$ conditions but not in normal and AWD conditions. This has not been shown previously. Moreover, at this locus, the allele group contributing for more number of tillers was present in the three highest yielding mutants (NH787, NH363 and NH686) under low $\mathrm{P}$ and also different from $\mathrm{N} 22$ allele type. In these three mutants, the allele for $\mathrm{K}-1$, (associated with tiller number in low $\mathrm{P}$ ) was different from that of N22. Increased tiller number under $\mathrm{P}$ deficiency is a very good indicator of $\mathrm{P}$ deficiency tolerance in rice (Wissuwa et al., 1998, 2002; Ni et al., 1998; Alam et al., 2009). At IIRR, we have been using tiller number as a surrogate for root traits in low $\mathrm{P}$ field. Wissuwa et al. (2002) reported that $80 \%$ of the variation for tiller number was explained by genetic variations at Pupl locus.

In the present study, RM263 was associated with yield per plant in all three treatments: normal, low $\mathrm{P}$ and AWD. The same marker was also associated with number of tillers and panicles in normal and AWD conditions. Luo et al. (2011) reported positive association of RM263 with 1,000 grain weight in the introgression lines of indica cultivar Guichao 2 and O. rufipogon. Marri et al. (2005) also reported RM263 flanking a major yield QTL qyld2.2 and grain number QTL gnp2.2 in interspecific $\mathrm{BC}_{2}$ testcross progeny (IR58025A/ $O$. rufipogon// IR580325B/// IR58025B//// KMR3). They also reported RM242 and RM205 on chromosome 9 flanking QTLs for yield (qtlp9.1) and grain weight ( $g w 9.2$ ). However, in the present study RM205 was linked with yield per plant and number of panicles in AWD conditions only and RM 242 with yield per plant only in normal conditions. RM242 was used in marker-assisted back-crossing to significantly increase root length under both irrigated and drought stress in Kalinga III (an Indian upland rice variety) using Azucena (an upland japonica variety from Philippines) as donor parent.

\section{Materials and methods}

\section{Plant materials}

A set of 67 EMS induced Nagina 22 (N22) mutant lines of $\mathrm{M}_{6}$ generation and their parent N22 (wild type) were used as experimental material. Panicle to row method was followed to advance generation from $\mathrm{M}_{2}$ to $\mathrm{M}_{6}$. 


\section{Field experiment}

The plants were grown during wet season 2012 at fields of Indian Institute of Rice Research (IIRR), Hyderabad (latitude and longitude: $17^{\circ} 22^{\prime} 31^{\prime \prime} \mathrm{N}$ and $78^{\circ} 28^{\prime} 27$ E) under the following three environments; a) normal plot $\left(15 \mathrm{mg} \mathrm{kg}^{-1}\right.$ Olsen $\mathrm{P}$ ) using normal irrigation practices b) low $\mathrm{P}$ plot (1.80-2.00 mg kg-1 Olsen P) using normal irrigation practices c) AWD practice in normal soil. The low $\mathrm{P}$ plot was developed by not giving any $\mathrm{P}$ fertilizers for the last 27 years, but supplied with $100 \mathrm{~kg} \mathrm{~N} \mathrm{ha}^{-1}$ and $60 \mathrm{~kg} \mathrm{~K} \mathrm{ha}^{-1}$ each season (Panigrahy et al., 2014). Plants were grown in 3 replications of 2 lines of each genotype and 22 plants per line with spacing of $20 \mathrm{~cm} \times 20 \mathrm{~cm}$ in each treatment. Irrigation management practices in AWD treatment were followed as described by Siopongco et al., 2013. At physiological maturity, the following morphological traits were studied viz., plant height (length of the tallest tiller upto tip of panicle in $\mathrm{cm}$ ), number of tillers, number of panicles (number of panicles with seeds exceeding 15\%), and yield/plant (mean weight of filled seeds from 22 plants).

\section{Genotyping}

Genomic DNA was extracted from leaves of 67 N22 mutant lines and N22 using Cetyl Trimethyl Ammonium Bromide extraction buffer. For genotyping, polymerase chain reaction (PCR) was done with 44 SSR markers from RM series (McCouch et al., 2002) and four Pupl gene specific markers (Chin et al., 2011). The amplified fragments were evaluated as present (1) and absent (0) bands.

\section{Genetic diversity and marker trait association analysis}

General statistics, Anova, correlation and significant analysis comparing with normal and stress conditions and also between mutants and parent N22 for phenotyping data were performed using Statistix 8.1.

Genetic diversity in mutants was evaluated considering phenotyping data from three tested treatments (normal, low P and AWD) and genotyping data of 44 SSR markers and four Pupl gene specific markers (95 polymorphic bands) using CLUSTER and Ward's MLM procedure in SAS program. Gower algorithm was used (Gower, 1971) to obtain the distance matrix for the use of the Ward grouping method. The ideal number of groups was decided according to the pseudo$\mathrm{F}$ and pseudo- $\mathrm{t}^{2}$ criteria (SAS Institute 2011). Hierarchical cluster analysis was performed using Ward minimum variance method and cophenetic correlation coefficient (Fit critera) using DARwin 5 software (web: http://darwin.cirad.fr/darwin), based on the distance matrix by the Gower algorithm. Dendrogram was constructed to estimate number of clusters.

Single marker analysis (SMA) was done using MINITAB V14.0 (Minitab Inc., State College, PA, USA) to find out association between each marker and each trait in the three environments.

\section{Conclusion}

Six mutants (NH787, NH686, NH669, NH363, NH355 and NH719) were identified as the best mutants based on their yield under all three conditions normal, low $\mathrm{P}$ and AWD and considered as gain of function mutants for low $\mathrm{P}$ tolerance. On the other hand, NH101 was identified as a loss of function mutant for flowering and yield under low P. Mutants were delineated into five groups. The pair NH664-NH427 were the closest and NH363-NH162 were the most dissimilar. In all, 15 markers out of 48 were associated with plant height, number of tillers, number of panicles and yield per plant based on single marker analysis. Significantly, Pupl gene specific marker, K-1 was associated with tiller number but only in low P conditions. The selected mutants and associated markers are a good genetic resource to breed for tolerance to low $\mathrm{P}$ and AWD conditions and also for discovering genes related to these desirable traits.

\section{Acknowledgements}

The authors thank Department of Biotechnology, Govt. of India for financial support (BT/PR9264/AGR/02/406(04)/2007) and Director IIRR for facilities. Conflict of Interest: All authors declare that they have no conflict of interest.

\section{References}

Alam MM, Hassanuzzaman M, Nahar K (2009) Tiller dynamics of three irrigated rice varieties under varying phosphorus levels. Am-Euras J Agron. 2(2): 89-94.

Aluwihare YC, Ishan1 M, Chamikara MDM (2016) Characterization and selection of phosphorus deficiency tolerant rice genotypes in Sri Lanka. Rice Sci. 23(4): 184195.

Ashley K, Cordell D, Mavinic D (2011) A brief history of phosphorus: from the philosopher's stone to nutrient recovery and reuse. Chemosphere. 84:737-746.

Barbe TD, do Amaral AT, Gonsalves LSA, Rodrigues R, Scapim CA (2010) Association between advanced generations and genealogy in inbred lines of snap bean by the Ward-Modified Location Model. Euphytica. 173: 337343.

Bhat R, Upadhyaya N, Chaudhury A, Raghavan C, Qiu F, Wang H, Wu J, McNally K, Leung H, Till B (2007) Chemical and irradiation induced mutants and tilling. In: Upadhyaya NM ( Ed) Rice Functional Genomics: Challenges, Progress and Prospects. Springer, New York. 148-180.

Bhuiyan SI (1992) Water management in relation to crop production: Case study on rice. Outlook Agr. 21(4): 293299.

Bouman BAM, Lampayan RM, Tuong TP (2007) Water management in irrigated rice: coping with water scarcity. International Rice Research Institute (IRRI), Los Baños, Philippines.54.

Caldwell DG, McCallum N, Shaw P, Muehlbauer GJ, Marshall DF, Waugh R (2004) A structured mutant population for forward and reverse genetics in Barley (Hordeum vulgare L.). Plant J. 40:143-150.

Chin JH, Gamuyao R, Dalid C, Bustamam M, Prasetiyono J, Moeljopawiro S, Wissuwa M, Heuer S (2011) Developing rice with high yield under phosphorus deficiency: Pupl sequence to application. Plant Physiol. 156: 1202-1216.

Chin JH, Lu XC, Haefele SM, Gamuyao R, Ismail A, Wissuwa M, Heuer S (2010) Development and application of gene-based markers for the major rice QTL phosphorus uptake 1. Theor Appl Genet. 120: 1073-1086.

Dkhar F, Rai M, Tyagi W (2014) Looking beyond PsTOL1: marker development for two rice genes showing differential expression in $\mathrm{P}$ deficient conditions. J Genet. 93(2): 573-577.

Franco J, Crossa J, Taba S, Shands H (2005) A sampling strategy for conserving genetic diversity when forming core subsets. Crop Sci. 45: 1035-1044. 
Gamuyao R, Chin JH, Pariasca-Tanaka J, Pesaresi P, Catausan S, Dalid C, Slamet-Loedin I, E. M. TecsonMendoza EM, Wissuwa M, Heuer S (2012) The protein kinase Pstoll from traditional rice confers tolerance of phosphorus deficiency. Nature. 488: 535-539.

Geleta N, and Heinrich G (2012) Classifying Ethiopian tetraploid wheat (Triticum turgidum 1.) landraces by combined analysis of molecular \& phenotypic data. Sci Technol Arts Res J. 1(1): 01-09.

Gemenet DC, Hash CT, Moussa D, Sanogo Ousmane S, Roger GZ, Willmar LL, Bettina IGH (2015) Phosphorus uptake and utilization efficiency in West African pearl millet inbred lines. Field Crop Res. 171: 54-66.

Ghaffari A, Gharechahi J, Nakhoda B, Salekdeh GH (2014) Physiology and proteome responses of two contrasting rice mutants and their wild type parent under salt stress conditions at the vegetative stage. J Plant Physiol. 171: 3144.

Goncalves LSA, Rodrigues R, Amaral AT, Karasawa M, Sudre CP (2009) Heirloom tomato gene bank: Assessing genetic divergence based on morphological, agronomic and molecular data using a Ward-Modified Location model. Genet Mol Res. 8: 364-374.

Goswami BR, Jignesh HK, Sandip KB (2013) Molecular diversity and association of simple sequence repeat markers with kernel mass in cultivated groundnut (Arachis hypogaea L.). Aust J Biol Sci. 7(8): 1152-1159.

Gower JC (1971) A general coefficient of similarity and some of its properties. Biometrics. 27: 857-874.

Henry IM, Nagalakshmi U, Lieberman MC, Ngo KJ, Krasileva KV, Vasquez-Gross H, Akhunova A, Akhunov E, Dubcovsky J, Tai TH, Comai L (2014) Efficient genome-wide detection and cataloging of EMS-induced mutations using exome capture and next-generation sequencing. Plant Cell. 26: 1382-1397.

Huang XY, Chao DY, Gao JP, Zhu MZ, Shi M, Lin HX (2009) A previously unknown zinc finger protein, dst, regulates drought and salt tolerance in rice via stomatal aperture control. Gene Dev. 23: 1805-1817.

Jagadish SVK, Craufurd PQ, Wheeler TR (2008) Phenotyping parents of mapping populations of rice for heat tolerance during anthesis. Crop Sci. 48: 1140-1146.

Jiang SY, Ramachandran S (2010) Natural and artificial mutants as valuable resources for functional genomics and molecular breeding. Int J Biol Sci. 6: 228-251.

Jones GPD, Blair GJ, Jessop RS (1989) Phosphorus efficiency in wheat-a useful selection criterion? Field Crop Res. 21: 257-264

Khan R, Khan H, Farhatullah, Harada K (2010) Evaluation of microsatellite markers to discriminate induced mutation lines, hybrid lines and cultigens in chickpea (Cicer arietinum L). Aust J Biol Sci. 4(5): 301-308.

Lampayan RM, Rejesus RM, Singleton GR, Bouman BAM (2015) Adoption and economics of alternate wetting and drying water management for irrigated lowland rice. Field Crop Res. 170: 95-108.

Lang NT, Buu BC (2006) Mapping QTLs for phosphorus deficiency tolerance in rice (Oryza sativa. L). Omonrice. 14: 1-9.

Leiser WL, Rattunde HFW, Weltzien E, Haussmann BIG (2014) Phosphorus uptake and use efficiency of diverse west and central african sorghum genotypes under field conditions in Mali. Plant Soil. 377: 383-394.

MacDonald GK, Bennett EM, Potter PA, Ramankutty N (2011) Agronomic phosphorus imbalances across the world's croplands. Proc Natl Acad Sci USA. 108(7): 30863091.
Markandeya G, Babu PR, Lachagari VBR, Reddy AMM, Wusirika R, Bennetzen JL (2007) Identification of stressresponsive genes in an indica rice (Oryza sativa L.) using ESTs generated from drought-stressed seedlings. J Exp Bot. 58: 253-265.

McCouch SR, Teytelman L, Xu YB, Lobos KB, Clare K, Walton M, Fu BY, R. Maghirang and et al. (2002) Development and mapping of 2240 new SSR markers for rice (Oryza sativa L.). DNA Res. 9: 199-207.

Mithra ASV, Kar MK., Mohapatra T, Robin S, Sarla N, Seshashayee M and et al. (2016) DBT propelled national effort in creating mutant resource for functional genomics in rice.Curr Sci. 110 (4): 543-548.

Mohapatra, T, Robin S, Sarla N, Sheshashayee M, Singh AK, Singh K, Singh NK, Amitha Mithra SV, Sharma RP (2014) EMS induced mutants of upland rice variety nagina22: Generation and characterization. Proc Indian Nat Sci Acad. 80: 163-172.

Nachimuthu VV, Raveendran M, Sudhakar D, Rajeswari S, Balaji AP, Govinthraj P, Karthika. GM, Swaminathan Suji K, Robin S (2015) Analysis of population structure and genetic diversity in rice germplasm using SSR markers: An initiative towards association mapping of agronomic traits in Oryza sativa. Rice. 8: 30.

Nakhoda B, Leung H, Mendioro MS, Mohammadi-Nejad G, Ismail AM (2012) Isolation, characterization, and field evaluation of rice (Oryza sativa L., Var. IR64) mutants with altered responses to salt stress. Field Crop Res. 127: 191-202.

Ni JJ, Wu P, Senadhira D, Huang N (1998) Mapping QTLs for phosphorus deficiency tolerance in rice (Oryza sativa L.). Theor Appl Genet. 97: 1361-1369.

Oliveira EJ, Oliveira OS, Santos VS (2015) Classification of cassava genotypes based on qualitative and quantitative data. Genet Mol Res. 14: 906-924.

Ortiz R, Crossa J, Franco J, Sevilla R, Burguen J (2008) Classification of peruvian highland maize races using plant traits. Genet Resour Crop Evol. 55: 151-162.

Panigrahy M, Rao DN, Yugandhar P, Raju NS, Krishnamurthy P, Voleti SR, Reddy GA, Mohapatra T, Robin S, Singh AK, Singh K, Sheshshayee M, Sharma RP, Sarla N (2014) Hydroponic experiment for identification of tolerance traits developed by rice Nagina 22 mutants to low-phosphorus in field condition. Arch Agron Soil Sci. 60: $565-576$

Parentoni SN, de Souza CL, Alves VMD, Gama EEG, Coelho AM and et al. (2010) Inheritance And Breeding Strategies For Phosphorus Efficiency In Tropical Maize (Zea mays L.). Maydica. 55: 1-15.

Pestanana RKN, Amorim EP, Ferreira CF, Amorim VBD, Oliveira LS, Ledo CAD and Silva SDE (2011) Agronomic and molecular characterization of gamma ray induced banana (Musa sp.) mutants using a multivariate statistical algorithm. Euphytica. 178: 151-158.

Poli Y, Basava RK, Panigrahy M, Vinukonda VP, Dokula NR, Voleti SR, Desiraju S, Neelamraju S (2013) Characterization of a Nagina22 rice mutant for heat tolerance and mapping of yield traits. Rice. 6: 36 .

Prasanth VV, Basava KR, Babu MS, VGN VT, Devi SJ, Mangrauthia SK and et al. (2016) Field level evaluation of rice introgression lines for heat tolerance and validation of markers linked to spikelet fertility. Physiol Mol Biol Plants. 22: 179-192.

Raghothama KG (1999) Phosphate acquisition. Annu Rev Plant Phys. 50: 665-693. 
Rahman MR and Bulbul SH. (2015) Adoption of water saving irrigation techniques for sustainable rice production in Bangladesh. eer. 3(1): 1-8.

Reis RV, Amorim EP, Amorim VBO, Ferreira CF, Pestana RKN, Ledo CAS, Gonçalves Z, Borém A (2015) Genetic dissimilarity and selection of putative mutants of Terra Maranhão plantain cultivar using the Ward-MLM strategy. Genet Mol Res. 14 (4): 15339-15348. Rejesus RM, Palis FG, Rodriguez DGP , Lampayan RM, Bouman BAM (2010) Impact of the alternate wetting and drying (AWD) water-saving irrigation technique: Evidence from rice producers in the Philippines. Food Policy. 36: 280-288.

Rose TJ, Mori A, Cecile CJ, Wissuwa M (2015) Screening for internal phosphorus utilisation efficiency: Comparison of genotypes at shoot $\mathrm{P}$ content is critical. Plant Soil. 401: 79-91.

Rose TJ, Pariasca-Tanaka J, Rose MT, Fukuta Y, Wissuwa M (2010) Genotypic variation in grain phosphorus concentration and opportunities to improve P-use efficiency in rice. Field Crops Res. 119: 154-160.

Rose TJ, Rose MT, Pariasca-Tanaka J, Heuer S, Wissuwa M (2011) The frustration with utilisation: Why have improvements in internal phosphorus utilisation efficiency in crops remained so elusive? Front Plant Sci. 2: 1-5.

Rose TJ, Wissuwa M (2012) Rethinking internal phosphorus utilization efficiency: A new approach is needed to improve PUE in grain crops. Adv Agron. 116: 185-217.

SAS Institute Inc 2011: SAS ${ }^{\circledR} 9.3$ System Options: Reference. 2nd Edn. SAS Institute Inc., Cary.

Shimizu A, Yanagihara S, Kawasaki S, Ikehashi H (2004) Phosphorus deficiency-induced root elongation and its QTL in rice (Oryza sativa L.). Theor Appl Genet. 109: 13611368.

Sikora P, Chawade A, Larsson M, Olsson J, Olsson O (2011) Mutagenesis as a tool in plant genetics, functional genomics, and breeding. Int J Plant Genomics. 2011: 1-13.

Singh CB, Aujla TS, Sandhu BS, Khera K (1996) Effects of transplanting data and irrigation regime on growth, yield and water use in rice (Oryza sativa) in Northern India. Indian J Agric Sci. 66: 137-141.

Singh SK, Roopa LG, Bhat KV, Suresh Babu G, Arya L, Verma M, Hussain Z, Roy S, Rathi RS, Misra AK (2012) Microsatellite markers revealed genetic diversity in mungbean mutant lines. Indian J Hill Fmg. 25(1): 38-43.

Siopongco JDLC, Wassmann R, Sander BO (2013) Alternate wetting and drying in Philippine rice production: Feasibility study for a clean development mechanism. IRRI Technical Bulletin No. 17. Los Baños, Philippines: International Rice Research Institute (IRRI).

Slade AJ, Fuerstenberg SI, Loeffler D, Steine MN, Facciotti D (2005) A reverse genetic, nontransgenic approach to wheat crop improvement by TILLING. Nat Biotechnol. 23: 75-81.

Sudre CP, Goncalves LS, Rodrigues R, do Amaral Junior AT, Riva-Souza EM, Bento Cdos S (2010) Genetic variability in domesticated Capsicum spp as assessed by morphological and agronomic data in mixed statistical analysis. Genet Mol Res. 9: 283-294.

Tiessen H (2008) Phosphorus in the global environment. In: White PJ, Hammond JP (Eds) Ecophysiology of plantphosphorus interactions. Springer, Netherlands. 1-8.

Till BJ, Burtner C, Comai L, Henikoff S (2004) Mismatch cleavage by single-strand specific nucleases. Nucleic Acids Res. 32: 2632-2641.

Till BJ, Cooper J, Tai TH, Colowit P, Greene EA, Henikoff S, Comai L (2007) Discovery of chemically induced mutations in rice by tilling. BMC Plant Biol. 7: 19.
Till BJ, Reynolds SH, Greene EA, Codomo CA, Enns LC, Johnson JE, Burtner C, Odden AR, Young K, Taylor NE and et al. (2003) Large-scale discovery of induced point mutations with high-throughput Tilling. Genome Res. 13: 524-530.

Tuong TP, Bouman BAM (2003) Rice production in waterscarce environments. In: Water productivity in agriculture Kjine et al. (Eds.). CAB International, Wallingford, UK.

Turki TA, Mohammed, Basahi A (2015) Assessment of ISSR based molecular genetic diversity of Hassawi rice in Saudi Arabia. Saudi J Biol Sci. 22: 5591-599.

Tyagi W, Rai M, Dohling AK (2012) Haplotype analysis for Pupl locus in rice genotypes of North-Eastern and Eastern India to identify suitable donors tolerant to low phosphorus. SABRAO J Breed Genet. 44: 398-405.

Vandamme E, Rose T, Saito K, Jeong K, Wissuwa M (2016) Integration of $\mathrm{P}$ acquisition efficiency, $\mathrm{P}$ utilization efficiency and low grain $\mathrm{P}$ concentrations into P-efficient rice genotypes for specific target environments. Nutr Cycl Agroecosyst. 104: 413-427.

White PJ, Hammond JP (2008) Phosphorus nutrition of terrestrial plants. In: White PJ, Hammond JP (Eds) The ecophysiology of plant-phosphorus interactions.. Dordrecht, The Netherlands. Springer, 51-81.

Wiel van de, Clemens CM, Linden van der, Gerard C, Scholten OE (2016) Improving phosphorus use efficiency in agriculture: Opportunities for breeding. Euphytica. 207 (1): $1-22$

Wissuwa M, Ae N (2001) Further characterization of two QTLs that increase phosphorus uptake of rice (Oryza sativa 1.) under phosphorus deficiency. Plant Soil. 237: 275-286.

Wissuwa M, Wegner J, Ae N, Yano M (2002) Substitution mapping of Pup1: A major QTL increasing phosphorus uptake of rice from a phosphorus-deficient soil. Theor Appl Genet. 105: 890-897.

Wissuwa M, Yano M, Ae N (1998) Mapping of QTLs for phosphorus-deficiency tolerance in rice (Oryza sativa L.). Theor Appl Genet. 97: 777-783.

Zhang Y, Tang Q, Peng S and et al. (2012) Water use efficiency and physiological response of rice cultivars under alternate wetting and drying conditions. Sci World J. 2012: 10.

Zhang YJ, Dong YJ, Zhang JZ, Xiao K, Xu JL, Terao H (2009) Mapping QTLs for eficiency phosphorus response to root-growth of rice seedling. Rice Genetics News letter. 25: $36-37$.

Zhi and Cui (2001) Irrigation techniques of water-efficient and sustainable humper yield for paddy rice. Program Report For 1997-2000. Wuhan University, China.

Zhou J, Wang F, Deng P, Jing W, Zhang W (2013) Characteization and mapping of a salt sensitive mutant in rice (Oryza sativa L.). J Integr Plant Biol. 55(6): 504-503. 